\title{
Quality of dementia clinical guidelines and relevance to the care of older people with comorbidity: evidence from the literature
}

This article was published in the following Dove Press journal:

Clinical Interventions in Aging

20 August 2014

Number of times this article has been viewed

\section{Gianfranco Damiani \\ Giulia Silvestrini \\ Lucrezia Trozzi \\ Donatella Maci \\ Lanfranco lodice \\ Walter Ricciardi}

Department of Public Health, Università Cattolica del Sacro Cuore, Largo Agostino Gemelli, Rome, Italy
Correspondence: Gianfranco Damiani Department of Public Health, Università Cattolica del Sacro Cuore, 8 Largo Agostino Gemelli, Rome 00I68, Italy Tel +390630I5 4396

Email gdamiani@rm.unicatt.it
Purpose: The aim of this paper was to explore the applicability of dementia clinical guidelines (CGs) to older patients, to patients with one or several comorbidities, and to both targets in order to evaluate if an association between the applicability and quality of the CGs exists.

Materials and methods: A systematic search strategy conducted on electronic databases identified CGs on diagnosis and treatment of dementia published from 2000 to 2013. In addition, websites of organizations devoted to the treatment and awareness of dementia were searched. The quality of evidence was assessed using the Appraisal of Guidelines Research and Evaluation (AGREE) instrument. Two investigators independently scored the relevance of the CGs by means of a specific tool. Descriptive and inferential analyses were performed (Mann-Whitney test, $0.05 \alpha$-level).

Results: Twenty-two CGs met our inclusion criteria. On average, the quality of the CGs was higher than $70 \%$ in three of six domains measured by the AGREE tool. The domains with lower mean scores (less than 50\%) were "Applicability" and "Editorial independence". Considering applicability to older patients, 20 CGs (91\%) addressed issues of treatment for older patients, five of them (23\%) classified older patients by age, and 13 CGs (60\%) addressed issues of comorbidity. Only seven (32\%) discussed the quality of evidence for patients with multiple comorbid conditions. Thirteen CGs (60\%) reported recommendations for patients with at least one comorbid condition, while seven of them (32\%) reported on several comorbid conditions. No statistically significant association between CG quality and relevance to care of older people with or without comorbidity was found $(P>0.05)$.

Conclusion: This study showed that dementia CGs poorly address treatment for older patients with comorbidities, regardless of their quality. Therefore, they scarcely satisfy the need of modern clinical practice.

Keywords: dementia, clinical guidelines, quality, older, comorbidity

\section{Background}

Dementia is a widespread clinical syndrome characterized by chronic, global, irreversible deterioration of memory, executive function, and personality severe enough to interfere with daily, social, and occupational functioning. ${ }^{1}$ In 2010 , it was estimated that 35.6 million people were living with dementia worldwide. The number of people with dementia will continue to grow, doubling every 20 years, particularly among the elderly and in countries in demographic transition. ${ }^{2}$

These days, Western Europe is the region with the highest number of people with dementia (7.0 million), with a prevalence of $7.2 \%$ in people over 60 years of age, closely followed by East Asia with 5.5 million, South Asia with 4.5 million, and North America with 4.4 million, where the prevalence of dementia in adults over 60 years old is $6.9 \% .^{3}$ 
It is widely known that caring for people with dementia requires a holistic approach, including the management of cognitive, behavioral, and psychological symptoms and the provision of social care. ${ }^{4}$ Furthermore, due to the higher prevalence of dementia among the elderly, the co-occurrence of other chronic conditions is frequent. Schubert et al found that patients with dementia attending primary care have on average 2.4 chronic conditions and receive 5.1 medications. ${ }^{5}$

Comorbid conditions can interact at various levels and overlap with each other during the management of treatment. Patients and caregivers can experience difficulties with the therapies prescribed for each comorbid condition, reducing adherence to the treatment plan and consequently diminishing its efficacy. Overlapping therapies could also increase the economic burden of disease. ${ }^{6}$

There is increasing evidence suggesting that clinical guidelines (CGs) directed at the management of chronic conditions should be modified for patients with comorbidities. Few researchers have analyzed CGs in order to evaluate their applicability to older patients and patients with several comorbidities, irrespective of the topic of the CGs. ${ }^{7-9}$ The literature showed a limited applicability of many current CGs to patients with comorbid conditions. ${ }^{10,11}$ With regard to the elderly, the evidence suggested a low representation of patients in advanced old age in CGs. ${ }^{9}$ When CGs discussed evidence for the elderly population, few of them addressed issues related to elderly patients with comorbidities. ${ }^{8,12}$

People with dementia are frequently old and with comorbid conditions. Although many studies have considered the complexity of providing medical care for patients with multiple comorbid conditions and dementia, to our knowledge there is no evidence about the relevance of dementia CGs to the care of older people with comorbidities.

Our aim was to explore the applicability of dementia CGs to elderly patients, to patients with one or several comorbidities, and to both targets by assessing how CGs addressed the issue of the treatment of elderly patients, of patients with one or several comorbidities and both targets and how CGs analyzed the evidence on this topic. Furthermore, the presence of specific recommendations for the management of both targets was evaluated. Finally, the association between the quality of the CGs and their applicability to elderly patients and to patients with comorbidity was also evaluated.

\section{Materials and methods}

\section{Guideline search and selection}

Dementia CGs were identified through searches in the Medline and Embase databases and via Google searches, using the following keywords (variously combined): "dementia", "treatment", "diagnosis", "clinical guidelines". In addition, the National Guideline Clearinghouse and International Guideline Database were searched.

To be included in this review, a CG had to: 1) be published from the 2000 to 2013; where CGs published were by the same organization and on the same topic, the latest version was included; 2) be published by European and North American associations; 3) be published in English; and 4) have as their main focus dementia treatment, considering together all the etiologies of dementia or dealing exclusively with the most prevalent etiologies, such as Alzheimer's disease or vascular dementia. CGs excluded were those that focused on low-prevalence types of dementia, such as frontotemporal dementia or dementia with Lewy bodies, and those that focused exclusively on prevention and/or early diagnosis and/or diagnosis of dementia.

In this review, we defined comorbid disease as the simultaneous occurrence of at least one medical condition in the same person in addition to dementia. ${ }^{13}$ Considering the complex relationship between dementia and depression in terms of definitions, epidemiology, related concepts, treatment, and emerging biomarkers, ${ }^{14}$ we chose to consider depression as a comorbidity only when in the CGs there was an explicit reference to diagnosed depression and not if the impact of depressive symptoms was considered alone. ${ }^{15,16}$

\section{Quality assessment and data abstraction}

Two reviewers assessed the quality of the CGs independently by using the Appraisal of Guidelines for Research and Evaluation (AGREE) II. This instrument has been validated and tested in several countries, and it is considered the best current tool for assessing the quality of a CG. ${ }^{17-21}$ AGREE II includes 23 items categorized in six domains, each capturing a separate dimension of CG quality. The first domain, "Scope and purpose" (three items) is concerned with the overall aim of a CG, specific clinical questions and/or problems, and the target patient population. The domain "Stakeholder involvement" (four items) focuses on the extent to which the CG reflects the views of its intended users and affected patients. "Rigor of development" (seven items) relates to the process used to gather and synthesize the evidence, as well as the methods used to develop, review, and update recommendations. "Clarity and presentation" (four items) deals with comprehensibility of the language applied in the CG and general CG format. The domain "Applicability" (three items) pertains to the likely organizational, behavioral, and economic implications of applying the CG. Finally, "Editorial independence" (two items) is concerned with the independence of the recommendations and acknowledgment 
of possible conflicts of interest of the CG developers. The instrument also includes two final overall assessment items that require the appraiser make overall judgments of the practice $C G$ and consider how they rated the 23 items. ${ }^{22}$ The scores, independently assessed by two reviewers involved in the revision process, were summed and standardized. The domain scores were calculated as the percentage of the maximum possible score.

To evaluate the applicability of the selected CGs to the care of older people, and/or of people with comorbidities, a specific instrument (developed by Boyd et al and then modified by Vitry and Zhang) was used. ${ }^{7,8}$ This instrument was composed of 14 items assessing whether or not CGs address treatment for older people and for people with several comorbid conditions, as well as patient-centered aspects, like patient preferences, for example.

To answer the research questions, the following items of the instrument were used:

- Guideline addressed treatment for patients with multiple comorbid conditions

- Guideline addressed treatment for older patients with multiple comorbid conditions

- Quality of evidence discussed for older patients

- Quality of evidence discussed for patients with multiple comorbid conditions

- Quality of evidence discussed for older patients with comorbid conditions

- Specific recommendations for patients with one comorbid condition

- Specific recommendations for patients with several comorbid conditions.

Two investigators extracted data independently, and agreement between the two reviewers was measured with Cohen's $\kappa$-statistic. Any disagreement was then resolved through discussion with a third reviewer. Data were summarized and tabulated, and descriptive statistics were calculated.

Finally, for the assessment of the association between CG quality and the relevance to care of older people with and without comorbidity, four of the 14 items of the checklist were considered (Guideline addressed treatments for older patients divided in different classes of age; Guideline addressed treatments for older patients with multiple comorbid conditions; Quality of evidence discussed for older patients; Quality of evidence discussed for older patients with multiple comorbid conditions). The mean AGREE domain score for CGs that resulted in having a positive score or not on each of the selected items was compared by means of the Mann-Whitney $U$ test at the 0.05 significance level.

\section{Results}

A total of $22 \mathrm{CGs}^{23-44}$ met our inclusion criteria, as shown in Figure 1. More than half of them were published in the US (12 of 22), with six and four in Canada and Europe, respectively. In five CGs, the intended user was explicitly general practitioners (GPs); eleven CGs were ascribed to specialists, caregivers, nurses, and others; and six did not mention GPs among the intended users. Diagnosis was discussed in 14 CGs, 17 CGs addressed both pharmacological and nonpharmacological treatment, four CGs were primarily concerned with pharmacological treatment, and only one was about nonpharmacological treatment (Table 1).

The individual standardized AGREE domain score for the 22 CGs selected and the mean score for every AGREE domain are shown in Table 2. The highest mean score was for "Scope and purpose" (75\%, standard deviation [SD] 14) followed by "Clarity of presentation" (75\%, SD 15), while the lowest was "Applicability" (45\%, SD 21), followed by "Editorial independence" (49\%, SD 34).

Table 3 summarizes the findings from the review about the relevance of dementia CGs for the treatment of older patients with comorbid conditions. Interrater agreement was generally from "moderate" (weighted $\kappa$ from 0.41 to 0.60 ) to "substantial" (weighted $\kappa$ from 0.61 to 0.80 ), according to the Landis and Koch scale, ${ }^{45}$ for almost all the domains. Nevertheless, some degree of variability remained within the "Burden of treatment" domain, where the $\kappa$-statistic scores varied from "fair" (weighted $\kappa=0.30$ ) to "almost perfect" (weighted $\kappa=0.84$ ).

Of the 22 CGs, 20 (91\%) addressed issues of treatment for older patients, five of which divided older patients into different classes of age (Table 3), and 13 (60\%) CGs addressed issues of comorbidity. The quality of evidence for older patients was

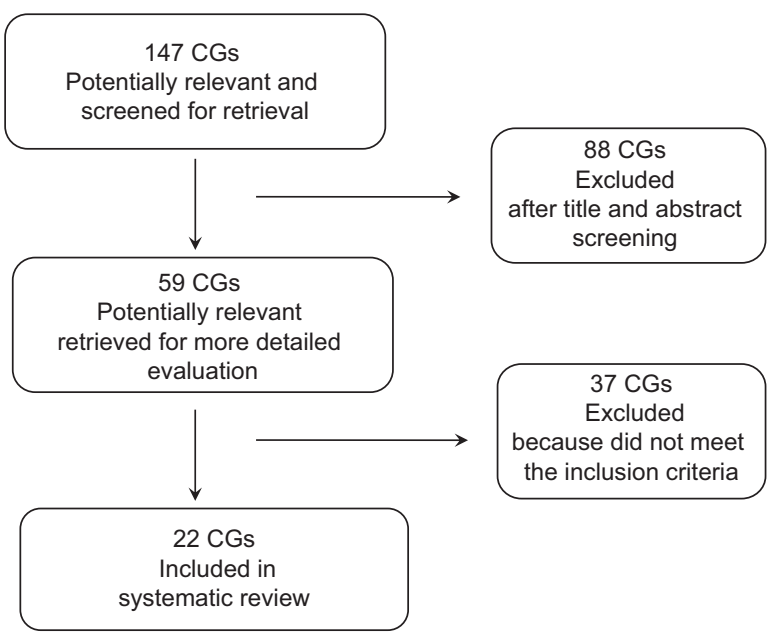

Figure I Flowchart of the clinical guidelines (CGs). 
Table I Basic characteristics of the selected guidelines $(n=22)$

\begin{tabular}{|c|c|c|c|c|c|}
\hline Study & Publication year & Country/region & Intended users & Diagnosis & Treatment \\
\hline Cantrell et $\mathrm{al}^{23}$ & 2012 & US & General practitioners/others & Yes & $\begin{array}{l}\text { Pharmacological } \\
\text { Nonpharmacological }\end{array}$ \\
\hline Bavazzano et $\mathrm{a}^{24}$ & 2011 & Italy & $\begin{array}{l}\text { General practitioners/ } \\
\text { specialists }\end{array}$ & Yes & $\begin{array}{l}\text { Pharmacological } \\
\text { Nonpharmacological }\end{array}$ \\
\hline Segal-Gidan et $\mathrm{al}^{25}$ & 2011 & US & General practitioners & Yes & $\begin{array}{l}\text { Pharmacological } \\
\text { Nonpharmacological }\end{array}$ \\
\hline Rossy et $\mathrm{al}^{26}$ & 2010 & Canada & General practitioners/others & Yes & $\begin{array}{l}\text { Pharmacological } \\
\text { Nonpharmacological }\end{array}$ \\
\hline Hort et $\mathrm{a}^{27}$ & 2010 & Europe & Specialists & Yes & $\begin{array}{l}\text { Pharmacological } \\
\text { Nonpharmacological }\end{array}$ \\
\hline $\begin{array}{l}\text { American Geriatrics } \\
\text { Society }{ }^{28}\end{array}$ & 2010 & US & $\begin{array}{l}\text { General practitioners/ } \\
\text { specialists/others }\end{array}$ & No & $\begin{array}{l}\text { Pharmacological } \\
\text { Nonpharmacological }\end{array}$ \\
\hline $\begin{array}{l}\text { Toward Optimized } \\
\text { Practice Program }\end{array}$ & 2008 & Canada & Specialists & Yes & $\begin{array}{l}\text { Pharmacological } \\
\text { Nonpharmacological }\end{array}$ \\
\hline Hogan et $a^{30}$ & 2008 & Canada & General practitioners/others & Yes & $\begin{array}{l}\text { Pharmacological } \\
\text { Nonpharmacological }\end{array}$ \\
\hline Hogan et $\mathrm{a}^{31}$ & 2008 & Canada & General practitioners & No & $\begin{array}{l}\text { Pharmacological } \\
\text { Nonpharmacological }\end{array}$ \\
\hline Hermann and Gauthier ${ }^{32}$ & 2008 & Canada & Specialists/others & Yes & Pharmacological \\
\hline Qaseem et $\mathrm{al}^{33}$ & 2008 & US & Specialists & No & Pharmacological \\
\hline Capezuti et al ${ }^{34}$ & 2008 & US & $\begin{array}{l}\text { General practitioners/ } \\
\text { specialists/others }\end{array}$ & No & $\begin{array}{l}\text { Pharmacological } \\
\text { Nonpharmacological }\end{array}$ \\
\hline $\begin{array}{l}\text { California Workgroup on } \\
\text { Guidelines for Alzheimer's } \\
\text { Disease Management }{ }^{35}\end{array}$ & 2008 & US & General practitioners & Yes & $\begin{array}{l}\text { Pharmacological } \\
\text { Nonpharmacological }\end{array}$ \\
\hline $\begin{array}{l}\text { National Collaborating } \\
\text { Centre for Mental Health }\end{array}$ & 2007 & UK & General practitioners/others & Yes & $\begin{array}{l}\text { Pharmacological } \\
\text { Nonpharmacological }\end{array}$ \\
\hline Rabins et $\mathrm{al}^{37}$ & 2007 & US & Specialists/others & No & $\begin{array}{l}\text { Pharmacological } \\
\text { Nonpharmacological }\end{array}$ \\
\hline Tilly et $\mathrm{al}^{38}$ & 2007 & US & General practitioners/others & No & $\begin{array}{l}\text { Pharmacological } \\
\text { Nonpharmacological }\end{array}$ \\
\hline Fillitt et $\mathrm{a}^{39}$ & 2006 & US & General practitioners/others & Yes & Pharmacological \\
\hline $\begin{array}{l}\text { Scottish Intercollegiate } \\
\text { Guidelines Network }{ }^{40}\end{array}$ & 2006 & Scotland & $\begin{array}{l}\text { General practitioners/ } \\
\text { specialists }\end{array}$ & Yes & $\begin{array}{l}\text { Pharmacological } \\
\text { Nonpharmacological }\end{array}$ \\
\hline Alexopoulos et al ${ }^{41}$ & 2005 & US & $\begin{array}{l}\text { General practitioners/ } \\
\text { specialists/others }\end{array}$ & No & $\begin{array}{l}\text { Pharmacological } \\
\text { Nonpharmacological }\end{array}$ \\
\hline Cummings et $\mathrm{al}^{42}$ & 2002 & US & General practitioners & Yes & $\begin{array}{l}\text { Pharmacological } \\
\text { Nonpharmacological }\end{array}$ \\
\hline Patterson et $\mathrm{al}^{43}$ & 2001 & Canada & General practitioners & Yes & Nonpharmacological \\
\hline Doody et $\mathrm{al}^{44}$ & 2001 & US & Specialists/others & No & Pharmacological \\
\hline
\end{tabular}

discussed in 18 (82\%) CGs, while the quality of evidence for patients with multiple comorbid conditions was considered in seven $(32 \%)$ of the 22 CGs analyzed by the review. Thirteen (60\%) CGs and seven (32\%) CGs, respectively, provided specific treatment recommendations for patients with at least one or more comorbid condition (Table 3).

More than half of the dementia CGs analyzed discussed the burden of treatment in the context of time from treatment to benefit, for patients and their caregivers, while less than $50 \%$ discussed the financial burden of treatment. Sixteen (73\%) CGs considered the preferences of patients, and eleven $(50 \%)$ especially considered end-of-life treatment.
The study of the association between CGs quality and the relevance to care of older people with and without comorbidities showed no statistically significant quality differences in the mean AGREE score for each domain, comparing CGs addressing older patients and comorbidity with those CGs who did not address older patients and comorbidities $(P>0.05$ for each item and each AGREE domain).

\section{Discussion}

Multiple medical comorbid conditions are very frequently encountered in the treatment of older adults with dementia, 
Table 2 Individual standardized Appraisal of Guidelines for Research and Evaluation (AGREE) domain scores (\%) for the guidelines studied, and mean and standard deviation (SD) for each domain

\begin{tabular}{|c|c|c|c|c|c|c|c|c|}
\hline Study & Year & $\begin{array}{l}\text { Countryl } \\
\text { region }\end{array}$ & $\begin{array}{l}\text { Scope and } \\
\text { purpose }\end{array}$ & $\begin{array}{l}\text { Stakeholder } \\
\text { involvement }\end{array}$ & $\begin{array}{l}\text { Rigor of } \\
\text { development }\end{array}$ & $\begin{array}{l}\text { Clarity of } \\
\text { presentation }\end{array}$ & Applicability & $\begin{array}{l}\text { Editorial } \\
\text { independence }\end{array}$ \\
\hline Cantrell et $\mathrm{a}^{23}$ & 2012 & US & $75 \%$ & $77 \%$ & $65 \%$ & $69 \%$ & $52 \%$ & $100 \%$ \\
\hline Bavazzano et a ${ }^{24}$ & 2011 & Italy & $72 \%$ & $62 \%$ & $52 \%$ & $81 \%$ & $44 \%$ & $100 \%$ \\
\hline Segal-Gidan et $\mathrm{a}^{25}$ & 2011 & US & $83 \%$ & $55 \%$ & $44 \%$ & $61 \%$ & $50 \%$ & $50 \%$ \\
\hline Rossy et $\mathrm{a}^{26}$ & 2010 & Canada & $92 \%$ & $87 \%$ & $93 \%$ & $97 \%$ & $67 \%$ & $79 \%$ \\
\hline Hort et $\mathrm{al}^{27}$ & 2010 & Europe & $81 \%$ & $77 \%$ & $49 \%$ & $83 \%$ & $23 \%$ & $50 \%$ \\
\hline American Geriatrics Society ${ }^{28}$ & 2010 & US & $42 \%$ & $12 \%$ & $7 \%$ & $47 \%$ & $2 \%$ & $0 \%$ \\
\hline Toward Optimized Practice Program ${ }^{29}$ & 2008 & Canada & $39 \%$ & $21 \%$ & $17 \%$ & $44 \%$ & $15 \%$ & $0 \%$ \\
\hline Hogan et $\mathrm{a}^{30}$ & 2008 & Canada & $64 \%$ & $83 \%$ & $46 \%$ & $69 \%$ & $37 \%$ & $75 \%$ \\
\hline Hogan et $a^{31}$ & 2008 & Canada & $67 \%$ & $67 \%$ & $40 \%$ & $83 \%$ & $46 \%$ & $71 \%$ \\
\hline Hermann and Gauthier ${ }^{32}$ & 2008 & Canada & $89 \%$ & $73 \%$ & $58 \%$ & $92 \%$ & $42 \%$ & $8 \%$ \\
\hline Qaseem et $\mathrm{al}^{33}$ & 2008 & US & $78 \%$ & $69 \%$ & $73 \%$ & $81 \%$ & $56 \%$ & $79 \%$ \\
\hline Capezuti et al ${ }^{34}$ & 2008 & US & $78 \%$ & $83 \%$ & $65 \%$ & $58 \%$ & $62 \%$ & $42 \%$ \\
\hline $\begin{array}{l}\text { California Workgroup on Guidelines } \\
\text { for Alzheimer's Disease Management }{ }^{35}\end{array}$ & 2008 & US & $86 \%$ & $71 \%$ & $32 \%$ & $86 \%$ & $40 \%$ & $0 \%$ \\
\hline $\begin{array}{l}\text { National Collaborating Centre } \\
\text { for Mental Health } \\
36\end{array}$ & 2007 & UK & $94 \%$ & $94 \%$ & $94 \%$ & $69 \%$ & $83 \%$ & $71 \%$ \\
\hline Rabins et $\mathrm{a}^{37}$ & 2007 & US & $78 \%$ & $88 \%$ & $68 \%$ & $89 \%$ & $46 \%$ & $96 \%$ \\
\hline Tilly et $a^{38}$ & 2007 & US & $81 \%$ & $50 \%$ & $48 \%$ & $67 \%$ & $21 \%$ & $17 \%$ \\
\hline Fillitt et al ${ }^{39}$ & 2006 & US & $78 \%$ & $50 \%$ & $23 \%$ & $67 \%$ & $38 \%$ & $58 \%$ \\
\hline Scottish Intercollegiate & 2006 & Scotland & $78 \%$ & $85 \%$ & $83 \%$ & $100 \%$ & $88 \%$ & $54 \%$ \\
\hline Guidelines Network ${ }^{40}$ & & & & & & & & \\
\hline Alexopoulos et $\mathrm{al}^{41}$ & 2005 & US & $69 \%$ & $54 \%$ & $61 \%$ & $58 \%$ & $27 \%$ & $0 \%$ \\
\hline Cummings et a $\mathrm{a}^{42}$ & 2002 & US & $67 \%$ & $60 \%$ & $32 \%$ & $78 \%$ & $63 \%$ & $46 \%$ \\
\hline Patterson et al ${ }^{43}$ & 2001 & Canada & $92 \%$ & $67 \%$ & $58 \%$ & $75 \%$ & $71 \%$ & $96 \%$ \\
\hline Doody et $\mathrm{al}^{44}$ & 2001 & US & $89 \%$ & $81 \%$ & $73 \%$ & $89 \%$ & $48 \%$ & $67 \%$ \\
\hline Mean (SD) & & & $75 \%(14 \%)$ & $67 \%(20 \%)$ & $54 \%(23 \%)$ & $75 \%(15 \%)$ & $45 \%(21 \%)$ & $49 \%(34 \%)$ \\
\hline
\end{tabular}

especially in primary care. ${ }^{5}$ However, our results suggest that CGs on dementia may have limited applicability to patients with comorbid conditions.

While CGs mainly addressed treatment for older patients, few of them provided specification about different classes of age. Cox et al reported this lack of stratification by age also. ${ }^{9}$ They remarked on this phenomenon even in other chronic disease CGs: it was found that only $31 \%$ of the CGs about several chronic diseases analyzed addressed the management of older patients, and an even smaller

Table 3 Clinical guidelines (CGs) and treatments for older patients

Total CGs n (\%)

Issues addressed

Guideline addressed treatment for older patients

Guideline addressed treatment for older patients divided in different classes of age

$20(91 \%)$

$5(23 \%)$

Guideline addressed treatment for patients with multiple comorbid conditions

$13(60 \%)$

Guideline addressed treatment for older patients with multiple comorbid conditions

$6(27 \%)$

Quality of evidence

Quality of evidence discussed for older patients

Quality of evidence discussed for patients with multiple comorbid conditions

Quality of evidence discussed for older patients with comorbid conditions

$7(32 \%)$

Recommendations

Specific recommendations for patients with one comorbid condition

$13(60 \%)$

Specific recommendations for patients with several comorbid conditions

$7(32 \%)$

Burden of treatment

Time needed to treat to benefit from treatment in the context of life expectancy discussed

$14(64 \%)$

Guideline discussed burden of comprehensive treatment on patients or caregivers

Guideline discussed patients' financial burden

$10(45 \%)$

Guideline discussed patients' quality of life

$22(100 \%)$

Patient preferences

Guideline discussed patients' preferences

$16(73 \%)$

Guideline discussed patients' preferences for end-of-life treatment

I I (50\%) 
percentage included an age-range comprehensive of over 80 year old patients.

The high percentage of dementia CGs that addressed treatment for older patients and discussed quality of evidence could be due to the high prevalence of dementia among the elderly, but the underrepresentation of individuals in advanced old age for this specific disease indicates that the evidence base for very old patients is limited. This could be ascribed to the fact that high-quality studies, such as randomized controlled trials, often exclude the elderly, especially those of advanced age, to describe the morbidity burden of their participants in published reports. ${ }^{46}$

The lack of specific evidence for elderly patients frequently patients with peculiar and multiple clinical, social, and organizational needs - may influence the physicians' ability to weigh $\mathrm{CG}$ benefits and harms and may reduce the CGs' role in guidance for decision making. Furthermore, there is evidence that elderly were usually the recipients of multiple evidence-based recommendations and treatment with a consistent effect on the burden of the disease for caregivers and patients themselves, especially in dementia treatment - instead of being the addressee of a hierarchical approach that prioritized the management of those conditions that primarily affect mortality, morbidity, and hospitalization.

With regard to issues of comorbidity, only $27 \%$ of the dementia CGs reviewed addressed treatment for older people with multiple comorbidities, and 32\% discussed the quality of evidence for the same target. Furthermore, when comorbidity was addressed, it was often discussed in general. Specific recommendations for at least one comorbid condition were present in almost $60 \%$ of the CGs, and half of these $(32 \%)$ contained recommendations for patients with several comorbid conditions. In particular, drug recommendations for management of patients with multiple pathological conditions are few or poorly rated in terms of priority, despite evidence that patients with dementia often suffer from many chronic diseases and the difficulty in managing a patient with dementia increases as the number of comorbid conditions increase. Frequently, treatment for the symptoms of dementia could interfere with one of the index illnesses, eg, if a cholinesterase inhibitor is being used to treat dementia in a patient who is also taking a drug with anticholinergic activity, pharmacological antagonism can result. This may render the dementia treatment ineffective. ${ }^{5}$ Furthermore, there is evidence that hospitalized older adults with dementia were less likely to be well managed in comparison with patients admitted for the same disease with no history of dementia. ${ }^{47}$
According to the quality evaluation, the CGs score well in three of the six domains measured by the AGREE instrument, even if the mean scores were globally lower compared to those of CGs about several other chronic diseases, as shown in a study conducted by Fortin et al. ${ }^{11}$ The "Scope and purpose" and "Clarity and presentation" domains obtained good scores, which demonstrates the scientific quality and validity of CGs. The domains with lower scores were "Applicability" and "Editorial independence". The low score of the Applicability criteria calls for a more pragmatic way of elaborating and formulating CGs in order to better fit the needs of targeted users. The absence of a significant association between quality and relevance to care of older people with and without comorbidity, highlights that a high quality score does not cause greater attention to comorbidity, and provides further evidence of the need for the development and validation of an instrument for assessing the applicability of CGs to patients with multimorbidity (especially for older adults with multimorbidity). ${ }^{12}$

Evidence-based CGs remain important and necessary tools to improve health-care quality for patients with dementia, although they may require some implementation. More detailed information on the management of very old patients, with a particular emphasis on comorbidity, should be included. An evidence-based approach for the refinement and development of CGs on the treatment of dementia in elderly with multimorbidity could be further enriched relying on multidimensional evaluation, considering also the costeffectiveness or cost savings of recommendations, possible disparities related to socioeconomic variables, and bioethical and organizational implications. ${ }^{48}$

Another approach increasingly advocated by those involved with processes to develop treatment CGs for multimorbidity is to take a patient-centered focus (eg, weighing the risks and benefits of treatments across a patient's health conditions) and provide recommendations that ensure flexibility that both patients, caregivers, and providers can accept. ${ }^{49}$

Furthermore, although detailed methods for developing recommendations for patients with multiple comorbidities are lacking, from the clinical area of respiratory disease practical CGs, a basis for a framework that will facilitate the integration of multiple comorbidities in the formulation and application of recommendations, was provided. ${ }^{50}$

Finally, in order to develop useful CGs for practitioners, providing concrete indications for the adequate management of each stage of the disease, CGs have to be short and concise, with a clear overview and layout. GPs have to collaborate more consistently with specialists and public health managers in producing evidence and recommendations, in line with the 
aim to gain a more patient-centered clinical practice, providing longitudinal studies, aimed at detecting the effectiveness of treatment of dementia, recruiting very old patients and considering comorbidity. Also the involvement of patients and caregivers is very relevant in the context of developing recommendations.

\section{Limitations and strengths}

The main strength of our study was that we systematically assessed the content of international dementia CGs, in terms of addressing care for older people and comorbidity. There were also some limitations. The CGs selected included only studies published in English. However, the inclusion criteria were wide, so there was good variability among the included CGs.

Furthermore, Boyd's instrument, though it responded well to our needs, has been recently developed. ${ }^{7}$ However, despite its recent adoption, this tool is widely utilized in the scientific literature, providing evidence of its applicability. ${ }^{8,9}$ Finally, the assessment of CG quality using the AGREE instrument may be influenced by the reviewer's background knowledge. However, to avoid biases as much as possible, each CG was evaluated by two reviewers independently.

\section{Conclusion}

This study showed that dementia CGs, regardless of their quality, poorly address treatment for elderly patients with comorbidities. Therefore, they scarcely satisfy the need of modern clinical practice. Development of CGs more concerned with multimorbidity, mainly in very old patients, is a cornerstone for the future of care. Therefore, GPs, patients, and caregivers should collaborate consistently with specialists and public health managers in producing evidence and recommendations in line with the aim to gain a tailored and more patient-centered clinical practice.

\section{Acknowledgments}

We would like to thank Dr Paolo Campanella for his very useful suggestions and for revising the final manuscript. This article is based on a research program titled "The impact of regionally implemented models of care for people with chronic disease", and funded by a 2012 public grant provided by the Italian National Centre for Disease Prevention and Control, to a network of research groups led by the Italian National Agency for Regional Health Services.

\section{Author contributions}

All authors made substantial contributions to conception and design, acquisition of data, or analysis and interpretation of data. All authors took part in either drafting or revising the article critically for important intellectual content. All authors approved the final version to be published.

\section{Disclosure}

The authors report no conflicts of interest in this work.

\section{References}

1. Grand JH, Caspar S, Macdonald SW. Clinical features and multidisciplinary approaches to dementia care. J Multidiscip Healthc. 2011;4:125-147.

2. World Health Organization. Dementia: A Public Health Priority. Geneva: WHO; 2012. Available from: http://www.who.int/mental_health/ publications/dementia_report_2012. Accessed March 27, 2014.

3. Duthey B. Background paper 6.11. Alzheimer disease and other dementias. 2013. Available from: http://www.who.int/medicines/areas/ priority_medicines/BP6_11Alzheimer.pdf. Accessed May 15, 2014.

4. Doody RS, Stevens JC, Beck C, et al. Practice parameter: management of dementia (an evidence-based review). Report of the Quality Standards Subcommittee of the American Academy of Neurology. Neurology. 2001;56(9):1154-1166.

5. Schubert CC, Boustani M, Callahan CM, et al. Comorbidity profile of dementia patients in primary care: are they sicker? J Am Geriatr Soc. 2006;54(1):104-109.

6. Boyd CM, Fortin M. Future of multimorbidity research: how should understanding of multimorbidity inform health system design? Public Health Rev. 2010;32(2):451-474.

7. Boyd CM, Darer J, Boult C, Fried LP, Boult L, Wu AW. Clinical practice guidelines and quality of care for older patients with multiple comorbid diseases: implications for pay for performance. JAMA. 2005;294(6): 716-724.

8. Vitry AI, Zhang Y. Quality of Australian clinical guidelines and relevance to the care of older people with multiple comorbid conditions. Med J Aust. 2008;189(7):360-365.

9. Cox L, Kloseck M, Crilly R, McWilliam C, Diachun L. Underrepresentation of individuals 80 years of age and older in chronic disease clinical practice guidelines. Can Fam Physician. 2011;57(7): e263-e269.

10. Lugtenberg M, Burgers JS, Clancy C, Westert GP, Schneider EC. Current guidelines have limited applicability to patients with comorbid conditions: a systematic analysis of evidence-based guidelines. PLoS One. 2011;6(10):e25987.

11. Fortin M, Contant E, Savard C, Hudon C, Poitras ME, Almirall J. Canadian guidelines for clinical practice: an analysis of their quality and relevance to the care of adults with comorbidity. BMC Fam Pract 2011;12:74.

12. Mutasingwa DR, Ge H, Upshur RE. How applicable are clinical practice guidelines to elderly patients with comorbidities? Can Fam Physician. 2011;57(7):e253-e262.

13. van den Akker M, Buntinx F, Roos S, Knottnerus JA. Comorbidity or multimorbidity: what's in a name? A review of the literature. Eur J Gen Pract. 1996;2(2):65-70.

14. Muliyala KP, Varghese M. The complex relationship between depression and dementia. Ann Indian Acad Neurol. 2010;13 Suppl 2: S69-S73.

15. Verkaik R, Francke AL, van Meijel B, Ribbe MW, Bensing JM. Comorbid depression in dementia on psychogeriatric nursing home wards: which symptoms are prominent? Am J Geriatr Psychiatry. 2009;17(7):565-573.

16. Kaszniak AW, Christenson GD. Differential diagnosis of dementia and depression. In: Storandt M, Vandenbos GR, editors. Neuropsychological Assessment of Dementia and Depression in Older Adults: A Clinician's Guide. Washington: American Psychological Association; 1994.

17. Stiegler M, Rummel C, Wahlbeck K, Kissling W, Leucht S. European psychiatric treatment guidelines: is the glass half full or half empty? Eur Psychiatry. 2005;20(8):554-558. 
18. Burgers JS, Cluzeau FA, Hanna SE, Hunt C, Grol R. Characteristics of high-quality guidelines: evaluation of 86 clinical guidelines developed in ten European countries and Canada. Int J Technol Assess Health Care. 2003;19(1):148-157.

19. Vlayen J, Aertgeerts B, Hannes K, Sermeus W, Ramaekers D. A systematic review of appraisal tools for clinical practice guidelines: multiple similarities and one common deficit. Int J Qual Health Care. 2005;17(3):235-242.

20. National Institute of Clinical Studies. Assessing the Implementability of Guidelines. Melbourne: NICS, 2006. Available from: http://www. nhmrc.gov.au/_files_nhmrc/file/nics/material_resources/summary_ report_assessing_implementability_guidelines.pdf. Accessed March 27, 2014.

21. MacDermid JC, Brooks D, Solway S, Switzer-McIntyre S, Brosseau L, Graham ID. Reliability and validity of the AGREE instrument used by physical therapists in assessment of clinical practice guidelines. BMC Health Serv Res. 2005;5(1):18.

22. AGREE Research Trust. Appraisal of Guidelines for Research and Evaluation II. AGREE Research Trust; 2009 Available from: http:// www.agreetrust.org/wp-content/uploads/2013/06/AGREE_II_Users_ Manual_and_23-item_Instrument_ENGLISH.pdf. Accessed March 27, 2014.

23. Cantrell L, Cefalu C, Dornberger S, et al. Dementia in the long term care setting. 2012. Available from: http://www.guideline.gov/content. aspx?id=45525. Accessed March 27, 2014.

24. Bavazzano A, Biagini CA, Bracco L, et al. Sindrome Demenza: Diagnosi e Trattamento. Consiglio Sanitario Regionale - Regione Toscana; 2011. Available from: https://www.ars.toscana.it/files/aree_intervento/ salute_di_anziani/lg_toscana_demenza_2011.pdf. Accessed March 27, 2014.

25. Segal-Gidan F, Cherry D, Jones R, Williams B, Hewett L, Chodosh J. Alzheimer's disease management guideline: update 2008. Alzheimers Dement. 2011;7(3):e51-e59.

26. Rossy D, Buchanan D, Burne D, et al. Caregiving strategies for older adults with delirium, dementia and depression 2010 supplement. 2010. Available from: http://www.guideline.gov/content.aspx?id=32418\&sea rch=Depressive+disorder,+NEC+in+ICD9CM_2013+. Accessed March 27, 2014.

27. Hort J, O'Brien JT, Gainotti G, et al. EFNS guidelines for the diagnosis and management of Alzheimer's disease. Eur J Neurol. 2010;17(10):1236-1248.

28. American Geriatrics Society. A guide to dementia diagnosis and treatment, 2010. Available from: http://dementia.americangeriatrics.org/ documents/AGS_PC_Dementia_Sheet_2010v2.pdf. Accessed March 27, 2014.

29. Toward Optimized Practice Program. Guideline for cognitive impairment: dementia - diagnosis to management. 2008. Available from: http:// www.topalbertadoctors.org/download/436/cognitive_impairment_ diagnosis_to_management_guideline.pdf. Accessed March 27, 2014.

30. Hogan DB, Bailey P, Black S, et al. Diagnosis and treatment of dementia: 4. Approach to management of mild to moderate dementia. CMAJ. 2008;179(8):787-793.

31. Hogan DB, Bailey P, Black S, et al. Diagnosis and treatment of dementia: 5. Nonpharmacologic and pharmacologic therapy for mild to moderate dementia. CMAJ. 2008;179(10):1019-1026.

32. Hermann N, Gauthier S. Diagnosis and treatment of dementia: 6. Management of severe Alzheimer disease. CMAJ. 2008;179(12):1279-1287.

33. Qaseem A, Snow V, Cross JT Jr, et al. Current pharmacologic treatment of dementia: a clinical practice guideline from the American College of Physicians and the American Academy of Family Physicians. Ann Intern Med. 2008;148(5):370-378.

34. Capezuti E, Zwicker D, Mezey M, Fulmer T, editors. Evidence-Based Geriatric Nursing Protocols for Best Practice. 3rd ed. New York: Springer; 2008.
35. California Workgroup on Guidelines for Alzheimer's Disease Management. Guideline for Alzheimer's Disease Management: Final Report 2008. Sacramento: California Workgroup on Guidelines for Alzheimer's Disease Management; 2008. Available from: http://www.cdph.ca.gov/ programs/alzheimers/Documents/professional_GuidelineFullReport. pdf. Accessed March 27, 2014.

36. National Collaborating Centre for Mental Health. Dementia. A NICESCIE Guideline on Supporting People with Dementia and Their Careers in Health and Social Care. Leicester, London: British Psychological Society, Royal College of Psychiatrists; 2008. Available from: http:// www.scie.org.uk/publications/misc/dementia/dementia-fullguideline. pdf. Accessed March 27, 2014.

37. Rabins PV, Blacker D, Rovner BW, et al. Practice Guideline for the Treatment of Patients with Alzheimer's Disease and Other Dementias. 2nd ed. Arlington (VA): American Psychiatric Association; 2007. Available from: http://psychiatryonline.org/pdfaccess.ashx?Resource $\mathrm{ID}=243205 \&$ PDFSource $=6$. Accessed March 27, 2014.

38. Tilly J, Reed P, Gould E, Fok A, editors. Dementia Care Practice Recommendations for Assisted Living Residences and Nursing Homes. Phase 3: End-of-Life Care. Chicago: Alzheimer's Association; 2007. Available from: http://www.asha.org/Members/ebp/compendium/ guidelines/Dementia-Care-Practice-Recommendations-for-AssistedLiving-Residences-and-Nursing-Homes--Phase-3-End-of-Life-Care. htm. Accessed March 27, 2014.

39. Fillit HM, Doody RS, Binaso K, et al. Recommendations for best practices in the treatment of Alzheimer's disease in managed care. Am J Geriatr Pharmacother. 2006;4 Suppl A:S9-S24.

40. Scottish Intercollegiate Guidelines Network. Management of patients with dementia. A national clinical guideline. 2006. Available from: http:// www.guideline.gov/content.aspx?id=8809. Accessed March 27, 2014.

41. Alexopoulos GS, Jeste DV, Chung H, Carpenter D, Ross R, Docherty JP. The expert consensus guideline series. Treatment of dementia and its behavioral disturbances. Introduction: methods, commentary, and summary. Postgrad Med. 2005;Spec No:6-22.

42. Cummings JL, Frank JC, Cherry D, et al. Guidelines for managing Alzheimer's disease: part II. Treatment. Am Fam Physician. 2002; 65(12):2525-2534.

43. Patterson C, Gauthier S, Bergman H, et al. The recognition, assessment and management of dementing disorders: conclusions from the Canadian Consensus Conference on Dementia. Can J Neurol Sci. 2001;28 Suppl 1:S3-S16.

44. Doody RS, Stevens JC, Beck C, et al. Practice parameter: management of dementia (an evidence-based review). Report of the Quality Standards Subcommittee of the American Academy of Neurology. Neurology. 2001;56(9):1154-1166.

45. Landis JR, Koch GG. The measurement of observer agreement for categorical data. Biometrics. 1977;33(1):159-174.

46. Scott IA, Guyatt GH. Cautionary tales in the interpretation of clinical studies involving older persons. Arch Intern Med. 2010;170(7):587-595.

47. Marengoni A, Rizzuto D, Wang HX, Winblad B, Fratiglioni L. Patterns of chronic multimorbidity in the elderly population. J Am Geriatr Soc. 2009;57(2):225-230.

48. EUnetHTA. HTA Core Model ${ }^{\circledR}$. Available from: http://www.eunethta. eu/hta-core-model. Accessed March 27, 2014.

49. Shekelle P, Woolf S, Grimshaw JM, Schünemann HJ, Eccles MP. Developing clinical practice guidelines: reviewing, reporting, and publishing guidelines; updating guidelines; and the emerging issues of enhancing guideline implementability and accounting for comorbid conditions in guideline development. Implement Sci. 2012;7:62.

50. Fabbri LM, Boyd C, Boschetto P, et al. How to integrate multiple comorbidities in guideline development: article 10 in integrating and coordinating efforts in COPD guideline development. An official ATS/ ERS workshop report. Proc Am Thorac Soc. 2012;9(5):274-281. 
Clinical Interventions in Aging

\section{Publish your work in this journal}

Clinical Interventions in Aging is an international, peer-reviewed journal focusing on evidence-based reports on the value or lack thereof of treatments intended to prevent or delay the onset of maladaptive correlates of aging in human beings. This journal is indexed on PubMed Central, MedLine,

CAS, Scopus and the Elsevier Bibliographic databases. The manuscript management system is completely online and includes a very quick and fair peer-review system, which is all easy to use. Visit http://www.dovepress. $\mathrm{com} /$ testimonials.php to read real quotes from published authors.

Submit your manuscript here: http://www.dovepress.com/clinical-interventions-in-aging-journal 